\title{
Up-Regulated Complement 3 Production by Toll-Like Receptor 9/Transforming Growth Factor-Beta 1/Complement 3 Pathway in Whole Blood Cells of Lupus Thrombocytopenia
}

\author{
Yi YUAN, ${ }^{1}$ Ling ZHAO, ${ }^{1}$ Ning MA, ${ }^{1}$ Zhuang YE, ${ }^{1}$ Zhenyu JIANG, ${ }^{1}$ Congqiu $\mathrm{CHU}^{2}$ \\ ${ }^{1}$ Department of Rheumatology and Immunology, Jilin University, Changchun, China \\ ${ }^{2}$ Department of Arthritis and Rheumatic Diseases, Oregon Health \& Science University and \\ Va Portland Health Care System, Oregon, USA
}

\begin{abstract}
Objectives: This study aims to assess the complement 3 (C3) expressions in whole blood cells and verify a pathway toll-like receptor 9 (TLR9)/ transforming growth factor-beta 1 (TGF- $\beta 1) / C 3$ for $C 3$ regulation in mediating thrombocytopenia (TCP) in patients with systemic lupus erythematosus (SLE).

Patients and methods: The study included 63 newly diagnosed SLE patients ( 2 males, 61 females; mean age 39.5 years; range 15 to 67 years). Whole blood messenger ribonucleic acid expression for C3, TLR9 and TGF- $\beta 1$ were measured by quantitative reverse transcription real-time polymerase chain reaction in SLE patients with TCP $(n=38)$ and age- and sex-matched SLE patients without TCP $(n=25)$ at baseline and in 10 SLE patients with TCP after four weeks of treatment. Whole blood cells from SLE patients with TCP were cultured in the presence of TLR9 ligand cytosine-phosphateguanine, recombinant human TGF- $\beta 1$, TGF- $\beta$ receptor inhibitor/activin receptor-like kinase inhibitor SB431542. TGF- $\beta 1$ and C3 levels in whole blood cells cultures were determined by quantitative reverse transcription real-time polymerase chain reaction and enzyme-linked immunosorbent assay. Results: Whole blood cells from SLE patients with TCP displayed an enhanced gene expression for C3, TLR9 and TGF- $\beta 1$ compared with that of SLE patients without TCP ( $p<0.01$ for $C 3, p<0.05$ for TLR9 and TGF- $\beta 1$ ). SLE patients with TCP had decreased plasma levels of C3 suggesting excessive consumption. In whole blood cell culture, engagement of TLR9 led to the increased gene expression of C3. Furthermore, TGF- $\beta 1$ inhibitor abolished TLR9 stimulation on C3 gene expression.

Conclusion: These results suggest that blood cells are the source of extra-hepatic synthesis of C3 in SLE patients with TCP and this synthesis of C3 was up-regulated by TLR9 via induction of TGF- $\beta 1$. Thus TLR9/TGF- $\beta 1 / C 3$ pathway might be in operation mediating lupus thrombocytopenia. Keywords: Complement 3; systemic lupus erythematosus; thrombocytopenia; toll-like receptor 9; transforming growth factor-beta 1.
\end{abstract}

Complement C3 (C3) has important effects on damage of target organs and tissues in systemic lupus erythematosus (SLE). Physiologically, C3 is mainly produced by hepatocytes, but it can also be induced in different types of cells in pathological conditions (extra-hepatic synthesis)., ${ }^{1,2}$ Previous studies demonstrated that an increase in C3 gene expression from extra-hepatic synthesis can mediate local tissue injury in target organs, such as in the kidney, heart, lung and intestines. ${ }^{3,4}$ It has been shown that extra-hepatic synthesis of $\mathrm{C} 3$ is tissue specific and can be regulated independently by inflammatory cytokines. ${ }^{4,5}$ SLE patients with thrombocytopenia (TCP) display decreased levels of plasma $C 3,{ }^{6,7}$ which is associated with an increased risk of disease relapse. ${ }^{8}$ However, the expression and regulation of extra-hepatic synthesis of C3 in whole blood cells in SLE patients with TCP remain elusive.

A previous study indicated an inverse correlation between toll-like receptor 9 (TLR9) expression by whole blood cells and plasma C3 concentration in active SLE. ${ }^{9}$ Therapeutic TLR9 
agonists are associated with an increased risk for development of TCP. ${ }^{10}$ These observations linked increased TLR9 activity and decreased plasma C3 levels in SLE patients with TCP. Engagement of TLR9 can activate nuclear factorkappa B signalling to induce transforming growth factor-beta 1 (TGF- $\beta 1$ ) expression by murine macrophages. ${ }^{11}$ Moreover, TGF- $\beta 1$ can induce C3 expression in human monocytes. ${ }^{12}$ Thus, we hypothesized that endogenous TLR9 agonists might activate TLR9 and induce C3 expression by up-regulating TGF- $\beta 1$ expression in blood cells during the pathogenic process of TCP in patients with SLE. In this study, we aimed to assess the C3 expressions in whole blood cells and verify a pathway TLR9/TGF- $\beta 1 / \mathrm{C} 3$ for C3 regulation in mediating TCP in patients with SLE.

\section{PATIENTS AND METHODS}

A total of 63 newly diagnosed SLE patients (2 males, 61 females; mean age 39.5 years; range 15 to 67 years) were enrolled from the Department of Rheumatology and Immunology of the First Hospital of Jilin University between October 2013 and April 2014. There were 38 SLE patients with TCP and 25 age- and sexmatched SLE patients without TCP. TCP was defined as a platelet count of less than $100 \times 10^{9} / \mathrm{L}$ in at least two occasions according to American College of Rheumatology criteria. ${ }^{13,14}$ Inclusion for enrolment were as follows: (i) All patients met the American College of Rheumatology revised criteria for the classification of SLE in $1997 ;^{13}$ (ii) with a duration of disease onset for less than three months; (iii) with no prior use of steroids or immunosuppressants before enrolling in the study. Exclusion criteria were as follows: (i) SLE patients with active infections or neoplastic disease at the time of the study; (ii) TCP patients with other potential causes including infection related TCP, drug-induced $\mathrm{TCP}$, hematological disease (based on bone marrow biopsy) or liver cirrhosis.

The study protocol was approved by the Institutional Medical Ethics Review Board of the First Hospital of Jilin University. A written informed consent was obtained from each patient. The study was conducted in accordance with the principles of the Declaration of Helsinki.
All 38 SLE patients with TCP received intravenous glucocorticoid therapy (methylprednisolone, $0.5-1 \mathrm{mg} \mathrm{kg} \mathrm{day}^{-1}$ ). In addition, 26 out of 38 SLE patients with TCP were treated with glucocorticoid and hydroxychloroquine $\left(400 \mathrm{mg}\right.$ day $\left.^{-1}\right)$. SLE patients with TCP were followed-up for four weeks. Gene expression of TLR9, TGF- $\beta 1$ and C3 were performed after treatment at four weeks in 10 SLE patients with TCP chosen randomly with the random number table. "Complete response" was defined as the platelet counts of $\geq 100 \times 10^{9} / \mathrm{L}$ and "response" was defined as the platelet counts between 30 and $100 \times 10^{9} / \mathrm{L}$, which reflected a $200 \%$ increase from the baseline platelet counts. ${ }^{14}$ Remission of lupus TCP includes "complete response" and "response".

Clinical and biological data of individual patients were collected, including age, sex, hematological changes, anti-double stranded deoxyribonucleic acid (anti-dsDNA) antibody titers, plasma C3 levels and Systemic Lupus Erythematosus Disease Activity Index (SLEDAI). ${ }^{15}$ Anti-dsDNA antibodies were measured by the Crithidia luciliae indirect immunofluorescence test, ${ }^{16}$ which is regarded as a reference method because of high specificity. ${ }^{17}$ An anti-dsDNA antibody titer of $\geq 1: 100$ was considered as "high" and $\leq 1: 32$ as "low".

Peripheral venous blood samples were collected before and after four weeks of immunosuppressive treatment. After centrifugation, one part of the whole blood cells was re-suspended in $1 \mathrm{~mL}$ TRIzol Reagent (Invitrogen, Carlsbad, CA, USA) and was stored at $-80^{\circ} \mathrm{C}$. The remaining whole blood cells were cultured in Roswell Park Memorial Institute 1640 medium in 12-well RNase-free tissue culture plates and stimulated with or without cytosine-phosphate-guanine (CpG) $(500 \mathrm{nM}$, Sangon Biotech, Shanghai, China), recombinant human TGF- $\beta 1$ (2.5 ng/mL, R\&D Systems, Inc., Minneapolis, MN, USA) and SB431542 (5 $\mu \mathrm{M}$, Sigma-Aldrich, Corp., St. Louis, MO, USA) at $37^{\circ} \mathrm{C}$ in $5 \%$ carbon dioxide atmosphere for 24 hours. The supernatants of cultured cells were harvested for analysis of TGF- $\beta 1$ and C3 levels by enzyme-linked immunosorbent assay. Whole blood cells were then harvested for ribonucleic acid (RNA) extraction.

The levels of TGF- $\beta 1$ and C 3 in the supernatants of cultured whole blood cells were determined by enzyme-linked immunosorbent assay using 
specific kits, according to the manufactures' instructions (eBioscience for TGF- $\beta 1$ ) and (CUSABIO for C3). Briefly, the samples were tested in duplicate and the concentrations of each cytokine were calculated, according to the standard curves established using recombinant molecules provided.

Total RNA was isolated from whole blood cells using TRIzol reagent. The purity of RNA was determined by Synergy H1 Hybrid Reader (Biotek, Instruments, Inc., Winooski, VT, USA) and the integrity of RNA was monitored by Agilent 2100 Bioanalyzer (Agilent Technologies, Santa Clara, USA). The RNA samples were reversely transcribed into complementary DNA using a PrimeScript RT Reagent Kit (TAKARA) and the relative levels of TLR9, C3 and TGF- $\beta 1$ to the control glyceraldehyde-3-phosphate dehydrogenase (GAPDH) were determined by quantitative reverse transcriptase polymerase chain reaction (qRT-PCR) in the ABI 7500 realtime PCR system (Applied Biosystems) using SYBR green PCR master mixed kit and specific primers. The results were normalized to the control and analyzed by $2^{-\Delta \mathrm{Ct}}$.

\section{Statistical analysis}

Statistical analysis was performed using GraphPad Prism 5.0 (GraphPad Software,
San Diego, CA, USA). Categorical variables (for example, percent of patients with high anti-dsDNA antibody titer) were analyzed by Fisher exact test. Continuous variables (such as laboratory tests) were analyzed by Student t-test, Wilcoxon signed rank test for paired samples and Mann-Whitney $U$ test for unpaired samples if the data were skewed. The potential relationship between measures was analyzed by Spearman rank correlation test. A $p$ value of less than 0.05 was considered statistically significant.

\section{RESULTS}

To investigate the extra-hepatic synthesis of $\mathrm{C} 3$ in whole blood cells of SLE patients with TCP, we recruited 38 SLE patients with TCP and 25 SLE patients without TCP. The demographic and clinical characteristics of these patients were shown in Table 1. There was no significant difference in the distribution of age and sex between the two groups. The SLEDAI scores in SLE patients with TCP were significantly higher than scores in SLE patients without TCP $(p=0.038)$. Furthermore, the percentage (63\%) of SLE patients with TCP with high anti-dsDNA antibody titer was significantly higher than that (28\%) in SLE patients without TCP, indicating that high anti-dsDNA antibody

Table 1. Demographic and clinical characteristics of participants

\begin{tabular}{|c|c|c|c|c|c|c|c|c|c|c|c|}
\hline & \multicolumn{5}{|c|}{ SLE with TCP } & \multicolumn{5}{|c|}{ SLE without TCP } & \multirow[b]{2}{*}{$p$} \\
\hline & $\mathrm{n}$ & $\%$ & Mean \pm SD & Median & Range & $\mathrm{n}$ & $\%$ & Mean \pm SD & Median & Range & \\
\hline Patients & 38 & & & & & 25 & & & & & \\
\hline \multicolumn{12}{|l|}{ Sex } \\
\hline Female & 37 & & & & & 24 & & & & & \\
\hline Male & 1 & & & & & 1 & & & & & \\
\hline Age (years) & & & & 37.5 & $24-52.3$ & & & & 41 & $22.5-46.5$ & 0.550 \\
\hline White blood cells $\left(\times 10^{9} / \mathrm{L}\right)$ & & & $4.2 \pm 2.4$ & & & & & $6.2 \pm 3.4$ & & & 0.007 \\
\hline \multicolumn{12}{|l|}{ Granulocytes } \\
\hline Absolute number $\left(\times 10^{9} / \mathrm{L}\right)$ & & & $2.9 \pm 2.1$ & & & & & $4.4 \pm 2.8$ & & & 0.028 \\
\hline Percentage & & & $67.0 \pm 13.6$ & & & & & $67.6 \pm 10.8$ & & & 0.833 \\
\hline \multicolumn{12}{|l|}{ Lymphocytes } \\
\hline Absolute number $\left(\times 10^{9} / \mathrm{L}\right)$ & & & $1.0 \pm 0.5$ & & & & & $1.4 \pm 0.7$ & & & 0.004 \\
\hline Percentage & & & $24.9 \pm 10.1$ & & & & & $24.6 \pm 8.8$ & & & 0.887 \\
\hline \multicolumn{12}{|l|}{ Monocytes $\left(\times 10^{9} / \mathrm{L}\right)$} \\
\hline Absolute number $\left(\times 10^{9} / \mathrm{L}\right)$ & & & $0.2 \pm 0.1$ & & & & & $0.4 \pm 0.2$ & & & 0.001 \\
\hline Percentage & & & $6.8 \pm 4.1$ & & & & & $6.8 \pm 3.6$ & & & 0.956 \\
\hline Hemoglobin $(\mathrm{g} / \mathrm{L})$ & & & $100.2 \pm 20.6$ & & & & & $101.7 \pm 17.5$ & & & 0.772 \\
\hline Platelet count $\left(\times 10^{9} / \mathrm{L}\right)$ & & & $61.8 \pm 27.8$ & & & & & $215.4 \pm 74.3$ & & & \\
\hline $\begin{array}{l}<0.0001 \\
\text { SLEDAI }\end{array}$ & & & & 16 & $8-21$ & & & & 10 & $5-165$ & 0.038 \\
\hline Anti-dsDNA antibody titre $\geq 1: 100$ & 24 & 63 & & 10 & $0-21$ & 7 & 28 & & 10 & $3-10.0$ & 0.010 \\
\hline Plasma C3 (g/L) & & & $0.6 \pm 0.0$ & & & & & $0.8 \pm 0.1$ & & & 0.005 \\
\hline
\end{tabular}


titer was associated with an increased risk for TCP in SLE (odds ratio $=4.4,95 \%$ confidence interval of 1.5-13.2, $\mathrm{p}=0.010)$. Although white blood cells, granulocytes, lymphocytes and monocytes counts in SLE patients with TCP were significantly lower than those in SLE patients without TCP ( $p=0.007$ for white blood cells, $p=0.028$ for granulocytes, $p=0.004$ for lymphocytes and $p=0.001$ for monocytes, respectively), percentages of granulocytes, lymphocytes and monocytes showed no difference between the two groups $(p=0.833$ for granulocytes, $p=0.887$ for lymphocytes and $p=0.956$ for monocytes, respectively). Plasma C3 levels in lupus TCP patients were significantly lower than levels in SLE patients without TCP $(\mathrm{p}=0.005)$. In contrast, the level of C3 messenger RNA (mRNA) expression in whole blood cells was significantly higher in lupus TCP patients compared with that in SLE patients without TCP $(p<0.01)$, (Figure 1c). Moreover, levels of TLR9 and TGF- $\beta 1$ mRNA expression by whole blood cells from SLE patients with TCP were also significantly higher than those in SLE patients with TCP ( $p<0.05$ for TLR9 and TGF- $\beta 1$, Figure $1 \mathrm{~b}$ and $1 \mathrm{c}$ ), indicating an increased gene expression of TLR9, TGF- $\beta 1$ and C3 by blood cells increased at baseline in SLE patients with TCP.

In SLE patients with TCP, TLR9 mRNA level in the group with high anti-dsDNA antibody titer was significantly higher than that in the low antidsDNA antibody titer group ( $p<0.05$, Figure 2a). Furthermore, the levels of plasma C3 negatively correlated with the SLEDAI scores and the titers of anti-dsDNA antibodies $(\mathrm{r}=-0.33, \mathrm{p}=0.0411$ for SLEDAI, Figure 2b; $r=-0.37, p=0.0207$ for anti-dsDNA antibody titers, Figure 2c). The levels of plasma C3 negatively correlated with the relative levels of $\mathrm{C} 3 \mathrm{mRNA}$ transcripts in whole blood cells $(r=-0.41, p=0.0113$, Figure 2d), but positively correlated with platelet counts in SLE patients with TCP $(r=0.37, p=0.0211$, Figure 2e). In addition, the levels of TGF- $\beta 1$ mRNA transcripts positively correlated with those of TLR9 $(r=0.62$, $p<0.0001$, Figure 2f) and C3 ( $r=0.45, p=0.0043$, Figure 2g) in whole blood cells from SLE patients with TCP. These data indicate that the excessive C3 gene expression by whole blood cells correlate with clinical parameters in SLE patients with TCP.

Following standard glucocorticoid and hydroxychloroquine therapies for four weeks, 10 SLE patients with TCP were chosen randomly with the random number table for measurement of TLR9, TGF- $\beta 1$ and C3 mRNA levels. There were seven out of 10 patients in remission ("complete response" and "response"). Analysis of these patients revealed that the SLEDAI scores of those patients who responded to therapies were significantly reduced while blood platelet counts and the levels of plasma C3 were significantly elevated compared with those of before treatment $(p<0.05$ for SLEDAI and platelet counts, $p<0.01$ for C3, Figure 3a-c). Further analysis indicated that the levels of TLR9, TGF- $\beta 1$ and C 3 mRNA transcripts in whole blood cells from those patients who responded to therapies were significantly (a)

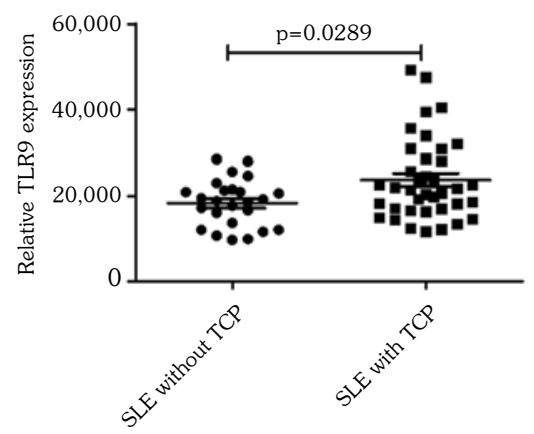

(b)

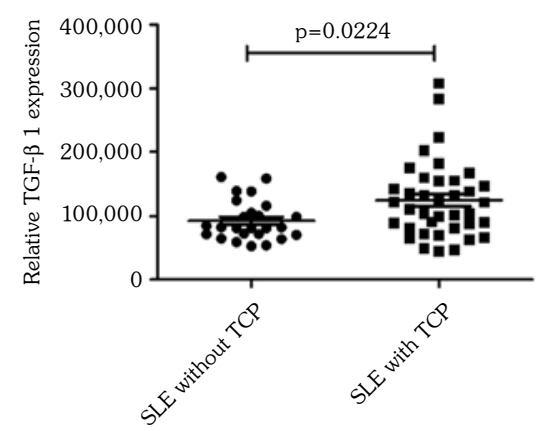

(c)

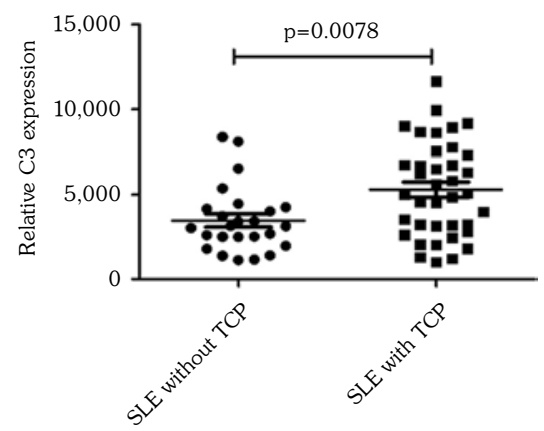

Figure 1. Increased gene expression of complement 3 (C3), toll-like receptor 9 (TLR9) and transforming growth factor-beta 1 (TGF- $\beta 1$ ) expressions in whole blood cells of systemic lupus erythematosus (SLE) patients with thrombocytopenia (TCP). Relative levels of (a) TLR9, (b) TGF- $\beta 1$ and (c) C3 messenger ribonucleic acid transcripts (mRNA) to glyceraldehyde3-phosphate dehydrogenase in whole blood cells of SLE patients were determined by quantitative reverse transcriptase polymerase chain reaction (qRT-PCR). Data are expressed as mean values of individual patients with thrombocytopenia $(n=38)$ and those without thrombocytopenia $(n=25)$. Lines reflect median values of individual groups. 
(a)

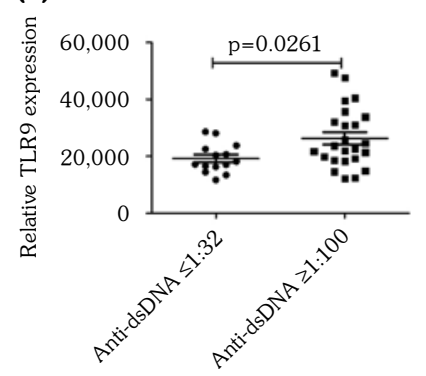

(b)

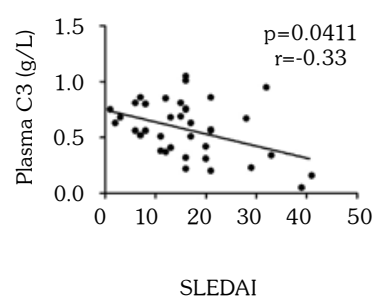

(c)

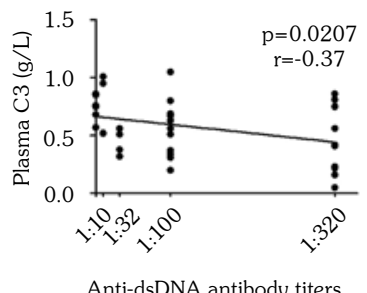

(d)

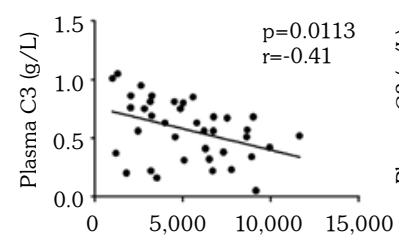

Relative C3 expression (e)

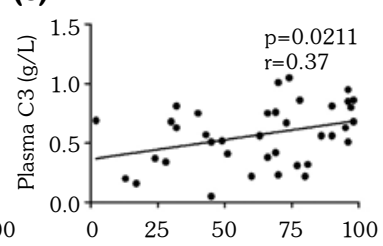

Platelet count $\left(\times 10^{9} / \mathrm{L}\right)$ (f)

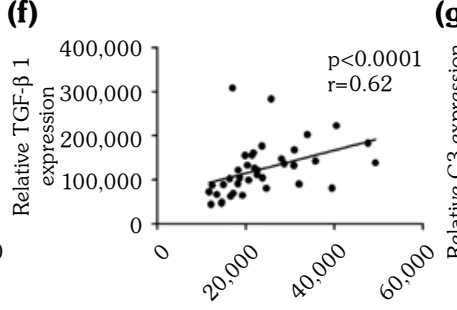

Relative TLR9 expression

(g)

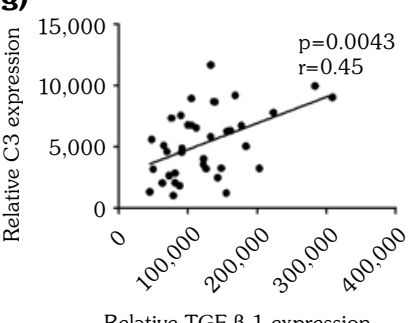

Figue 2. Correlations between clinical parameters and levels of toll-like receptor 9 (TLR9), transforming growth factor-beta 1 (TGF- $\beta 1$ ) and complement 3 (C3) messenger ribonucleic acid (mRNA) in whole blood cells from systemic lupus erythematosus (SLE) patients with thrombocytopenia (TCP). In SLE patients with TCP, TLR9 mRNA level in group with high anti-double stranded deoxyribonucleic acid (anti-dsDNA) antibody titer was significantly higher than that in low anti-dsDNA antibody titer group (a). Furthermore, levels of plasma C3 were negatively correlated with Systemic Lupus Erythematosus Disease Activity Index scores and titers of anti-dsDNA antibodies (b, c). Levels of plasma C3 are correlated negatively with levels of C3 mRNA transcripts, but correlated positively with blood platelet counts (d, e). Levels of TGF- $\beta 1$ mRNA transcripts are correlated positively with levels of TLR9 and C3 mRNA transcripts in whole blood cells (f, $\mathbf{g})$. Data are mean values of individual SLE patients with TCP $(\mathrm{n}=38)$.

lower than those of before treatment $(p<0.05$ for all, Figure $3 \mathrm{~d}-\mathrm{f}$ ). These results indicated that the standard therapies reduced disease severity and TLR9, TGF- $\beta 1$ and C3 expression in whole blood cells in SLE patients with TCP.

To understand the mechanisms of up-regulating C3 expression, we examined the possibility of the TLR9/TGF- $\beta 1 /$ C3 pathway in SLE patients with TCP. Whole blood cells were isolated from SLE patients with TCP and stimulated with TLR9 agonist CpG. We found that treatment with CpG significantly increased the levels of TGF- $\beta 1$ in whole blood cells (Figure $4 \mathrm{a}$ and b). We also found that stimulation with TGF- $\beta 1$ significantly increased C3 expression; while treatment with SB431542, the TGF- $\beta$ receptor inhibitor/activin receptor-like kinase (RI/ALK) inhibitor, significantly reduced $\mathrm{C} 3$ expression in whole blood cells (Figure $4 \mathrm{c}$ and $\mathrm{d}$ ). Furthermore, treatment with $\mathrm{CpG}$ to activate the TLR9 also increased significantly the levels of C3 expression in whole blood cells, which was completely abrogated by treatment with SB431542 (Figure $4 e$ and f). Thus, activation of TLR9 stimulated C3 expression by up-regulating TGF- $\beta 1$ expression in whole blood cells in vitro.

\section{DISCUSSION}

In the current study, we found that $\mathrm{C} 3$ gene expression was excessive in whole blood cells from lupus TCP patients indicating increase of extrahepatic synthesis of $\mathrm{C} 3$. The increased $\mathrm{C} 3$ gene expression was associated with increased gene expression of TLR9 and TGF- $\beta 1$. Furthermore, we demonstrated by in vitro experiments that TLR9 activation induced $\mathrm{C} 3$ expression was through up-regulating TGF- $\beta 1$ expression. These results suggest that the TLR9/TGF- $\beta 1 / \mathrm{C} 3$ pathway may be in operation in the pathogenesis of SLE with TCP.

It is conceivable that the increased C3 expression in whole blood cells of SLE patients 
(a)

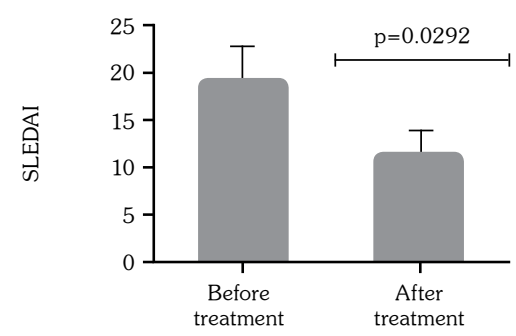

(d)

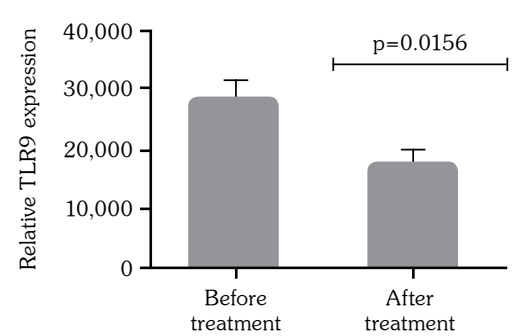

(b)

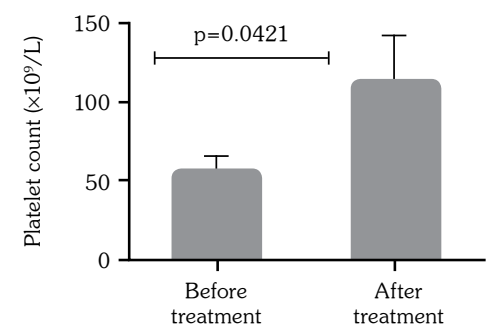

(e)

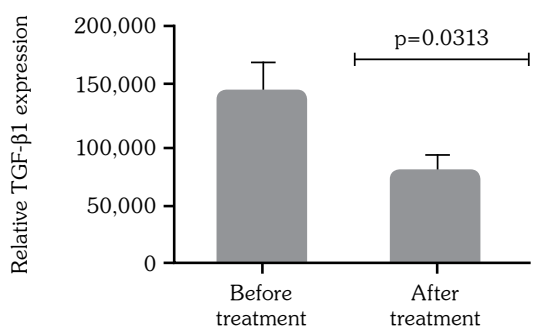

(c)

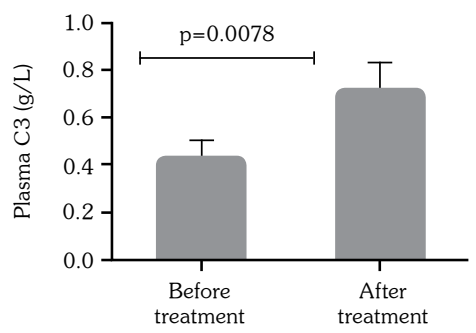

(f)

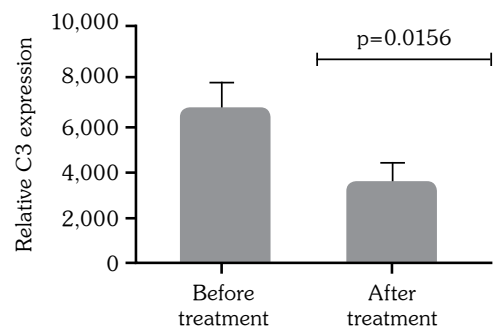

Figure 3. Therapy altered clinical parameters and toll-like receptor 9 (TLR9), transforming growth factor-beta 1 (TGF- $\beta 1$ ) and complement 3 (C3) expression in systemic lupus erythematosus (SLE) patients with thrombocytopenia (TCP). The Systemic Lupus Erythematosus Disease Activity Index scores (a), blood platelet counts (b) and plasma C3 (c) in individual SLE patients with thrombocytopenia who responded to standard therapy were measured and levels of TLR9, TGF- $\beta 1$ and C3 messenger ribonucleic acid transcripts (d-f) in those responding to standard therapy were detected by quantitative reverse transcriptase polymerase chain reaction at baseline and four weeks after treatment. Data are expressed as mean \pm standard error of mean of each group $(n=7)$ per time point group.

with TCP is resulted from an increased proportion of white blood cells. However, there was no difference found in proportions of granulocytes, lymphocytes or monocytes between SLE patients with TCP and SLE patients without TCP. On the contrary, the absolute numbers of these white blood cells in SLE patients with TCP were even lower than those of SLE patients without TCP. Thus, the TLR9/TGF- $\beta 1 / C 3$ pathway is enhanced in SLE patients with TCP.

We found that engagement of TLR9 by CpG promotes TGF- $\beta 1$ and $\mathrm{C} 3$ expression in blood cells, extending previous observations that $\mathrm{CpG}$ stimulated TGF- $\beta 1$ expression in murine bone marrow-derived macrophages. ${ }^{11}$ Moreover, treatment with TGF- $\beta 1$ stimulated C3 expression while treatment with TGF- $\beta$ RI/ALK inhibitor SB431542 decreased C3 expression in blood cells. Our findings extended the observation that TGF- $\beta$ induces acute-phase proteins, such as C3, in monocytes and hepatocytes. ${ }^{12,18,19}$ Finally, treatment with TGF- $\beta$ RI/ALK inhibitor abrogated the $\mathrm{CpG}$-induced $\mathrm{C} 3$ expression in blood cells. These three lines of evidence clearly demonstrated the presence of the TLR9/TGF- $\beta 1 /$ C3 pathway in SLE patients with TCP. Therefore, we identified a new pathway for $\mathrm{C} 3$ regulation in whole blood cells of lupus TCP in humans.

Hypocomplementemia is common in active SLE. A previous study on lupus has noticed that excessive consumption of plasma C3 leads to hypocomplementemia. ${ }^{20} \mathrm{~A}$ study on antiphospholipid antibody syndrome suggests that hypocompelmentemia (typically low C3 and C4) is due to complement consumption rather than complement deficiency. ${ }^{21}$ Moreover, excessive activation of complement mediates early platelet destruction in SLE. ${ }^{22}$ In our study, there was discrepancy between serum C3 level and C3 transcription level in whole blood cell in SLE patients with TCP. This disparity suggests that an increase in $\mathrm{C} 3$ production may compensate the excessive consumption of $\mathrm{C} 3$ protein for immune attack of thrombocytes.

Systemic lupus erythematosus patients with TCP are treated with glucocorticoids and hydroxychloroquine, which can inhibit the binding of DNA to TLR9 and the nuclear factor-kappa B 
(a)

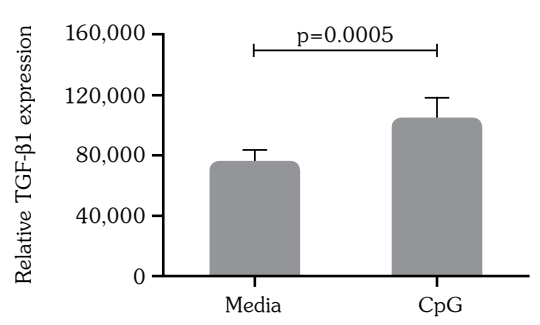

(d)

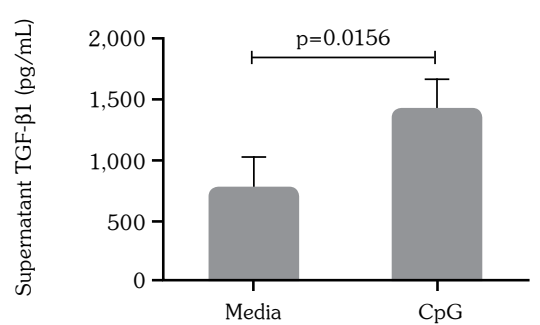

(b)

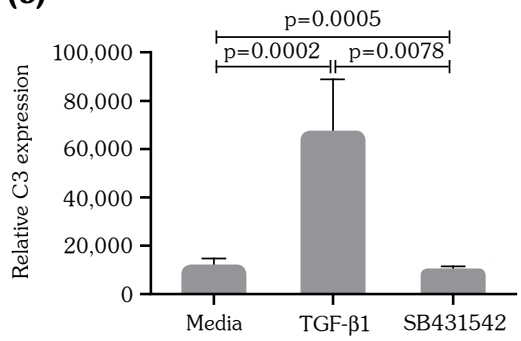

(e)

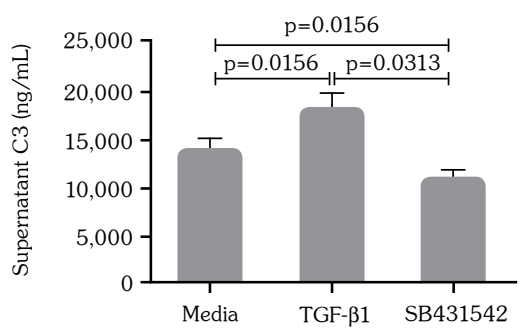

(c)

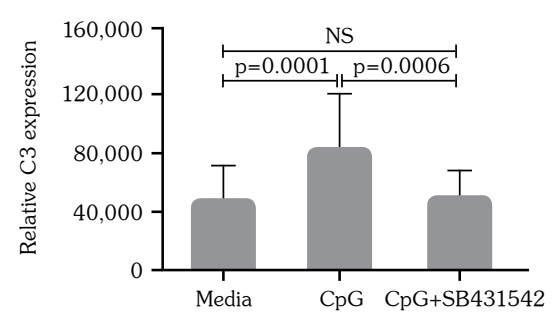

(f)

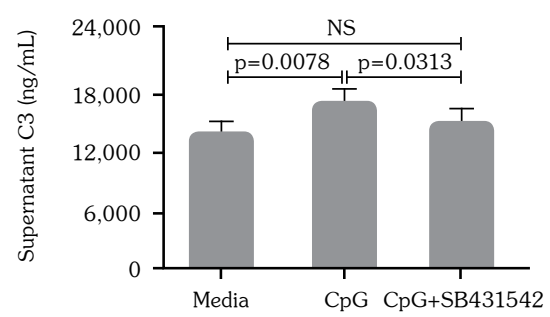

Figure 4. Toll-like receptor 9 (TLR9) activation stimulated complement 3 (C3) expression by inducing transforming growth factor-beta 1 (TGF- $\beta 1$ ) production in whole blood cells in systemic lupus erythematosus (SLE) patients with thrombocytopenia (TCP). Whole blood cells from SLE patients with TCP were isolated and stimulated with or without $500 \mathrm{nM}$ cytosine-phosphate-guanine, $2.5 \mathrm{ng} / \mathrm{mL}$ of TGF- $\beta 1$ or $5 \mu \mathrm{M}$ SB431542 for 24 hours, and some cells were treated with or without cytosine-phosphate-guanine alone or combined with SB431524 for 24 hours. Supernatants were harvested for measuring levels of C3 and TGF- $\beta 1$ by enzyme-linked immunosorbent assay. Relative levels of C3 and TGF- $\beta 1$ mRNA transcripts to glyceraldehyde-3-phosphate dehydrogenase in cultured blood cells were determined by quantitative reverse transcriptase polymerase chain reaction. Data are expressed as the mean \pm standard error of mean of each group from three separate experiments ( $n=8$, per group). Levels of C3 and TGF- $\beta 1$ mRNA transcripts (a, $\mathbf{c}, \mathbf{e})$ and levels of C3 and TGF- $\beta 1$ proteins $(\mathbf{b}, \mathbf{d}, \mathbf{f})$ are shown.

activation. ${ }^{23-25}$ We found that SLE patients with TCP responding to the standard therapies displayed significantly decreased disease severity, reduced levels of TLR9 and TGF- $\beta 1$ and C3 expression in blood cells, but increased levels of plasma C3 and platelet counts. These findings support the notion that glucocorticoid can inhibit endogenous DNA-activated TLR9 and nuclear factor-kappa $B$ activation in SLE patients with TCP. ${ }^{26}$ Thus, blocking TLR9 could down-regulate C3 gene expression in whole blood cells, which may lead to reduced complement mediated destruction of thrombocytes.

We demonstrated that whole blood cells are sites of extra-hepatic synthesis C3 in lupus TCP, and this synthesis can be regulated by the TLR9/ TGF- $\beta 1 / C 3$ pathway. Extra-hepatic synthesis of C3 in mononuclear phagocytes has been noticed long ago, and this local synthesis of complement at inflammation site may be of importance in immunopathological conditions. ${ }^{4,27}$ Furthermore, complements are implicated in participation in antibody mediated destruction of thrombocytes in periphery of patients with active lupus. ${ }^{28-31}$ Based on these studies, we hypothesize that whole blood cells' synthesis of C3 mediate local injury on platelets in SLE patients with TCP. However, we just observed the correlation but have not explored the causal relationship between the pathway and lupus TCP in current study. Further studies are needed on this issue.

We verified the TLR9/TGF- $\beta 1 / \mathrm{C} 3$ pathway on the basis of whole blood culture, because it mimics the complicated endogenous environment of human body and contains all the original elements which influence immune system. ${ }^{32}$ Moreover, whole blood assay avoids possible impacts on blood cells during cell separation procedures. However, whole blood cell culture will not allow precise identification of effector cells in this C3 regulation pathway. Therefore, further studies are needed to delineate precisely which cell types in lupus TCP patients 
are responsible for activated TLR9 that leads to increased expression of TGF- $\beta 1$ and C3.

There are limitations in the current study. The first is the relative smaller sample size in patients who have been chosen for mRNA detection after treatment. Further studies with a larger population are required to validate these findings. The second is the unclearness of casual relationship between the pathway and TCP. Further studies are needed to verify whether the activation of the TLR9/TGF- $\beta 1 / \mathrm{C} 3$ pathway in whole blood lead to TCP.

\section{Acknowledgements}

We thank the members of the hospital for their contributions to the immunological characterization of the patients. We thank all the patients and their family for their support and cooperation.

\section{Declaration of conflicting interests}

The authors declared no conflicts of interest with respect to the authorship and/or publication of this article.

\section{Funding}

The authors received no financial support for the research and/or authorship of this article.

\section{REFERENCES}

1. Naughton MA, Botto M, Carter MJ, Alexander GJ, Goldman JM, Walport MJ. Extrahepatic secreted complement C3 contributes to circulating C3 levels in humans. J Immunol 1996;156:3051-6.

2. Reis ES, Barbuto JA, Isaac L. Human monocytederived dendritic cells are a source of several complement proteins. Inflamm Res 2006;55:179-84.

3. Passwell J, Schreiner GF, Nonaka M, Beuscher $\mathrm{HU}$, Colten HR. Local extrahepatic expression of complement genes $\mathrm{C} 3$, factor $\mathrm{B}, \mathrm{C} 2$, and $\mathrm{C} 4$ is increased in murine lupus nephritis. $\mathrm{J}$ Clin Invest 1988;82:1676-84.

4. Falus A. Regulation of complement biosynthesis by tissue-specific and hormonal factors. Immunol Lett 1990;24:227-30.

5. Falus A, Beuscher HU, Auerbach HS, Colten HR. Constitutive and IL 1-regulated murine complement gene expression is strain and tissue specific. J Immunol 1987;138:856-60.

6. Ziakas PD, Giannouli S, Zintzaras E, Tzioufas AG, Voulgarelis M. Lupus thrombocytopenia: clinical implications and prognostic significance. Ann Rheum Dis 2005;64:1366-9.
7. Ktona E, Barbullushi M, Backa T, Idrizi A, Shpata V, Roshi E. Evaluation of thrombocytopenia in systemic lupus erythematosus and correlation with different organs damages. Mater Sociomed 2014;26:122-4.

8. Ziakas PD, Poulou LS, Giannouli S, Tzioufas AG, Voulgarelis M. Thrombocytopenia in lupus: baseline C3 as an independent risk factor for relapse. Ann Rheum Dis 2007;66:130-1.

9. Ghaly NR, Kotb NA, Nagy HM, Rageh el SM. Toll-like receptor 9 in systemic lupus erythematosus, impact on glucocorticoid treatment. J Dermatolog Treat 2013;24:411-7.

10. Qin M, Li Y, Yang X, Wu H. Safety of Toll-like receptor 9 agonists: a systematic review and meta-analysis. Immunopharmacol Immunotoxicol 2014;36:251-60.

11. Chow EK, O'connell RM, Schilling S, Wang XF, Fu XY, Cheng G. TLR agonists regulate PDGF-B production and cell proliferation through TGF-beta/ type I IFN crosstalk. EMBO J 2005;24:4071-81.

12. Høgåsen AK, Hestdal K, Høgåsen K, Abrahamsen TG. Transforming growth factor beta modulates C3 and factor B biosynthesis and complement receptor 3 expression in cultured human monocytes. J Leukoc Biol 1995;57:287-96.

13. Hochberg MC. Updating the American College of Rheumatology revised criteria for the classification of systemic lupus erythematosus. Arthritis Rheum 1997;40:1725.

14. Stasi R. Immune thrombocytopenia: pathophysiologic and clinical update. Semin Thromb Hemost 2012;38:454-62.

15. Bombardier C, Gladman DD, Urowitz MB, Caron $\mathrm{D}$, Chang $\mathrm{CH}$. Derivation of the SLEDAI. A disease activity index for lupus patients. The Committee on Prognosis Studies in SLE. Arthritis Rheum 1992;35:630-40.

16. Somerfield SD, Roberts MW, Booth RJ. Doublestranded DNA antibodies: a comparison of four methods of detection. J Clin Pathol 1981;34:1032-5.

17. Haugbro K, Nossent JC, Winkler T, Figenschau Y, Rekvig OP. Anti-dsDNA antibodies and disease classification in antinuclear antibody positive patients: the role of analytical diversity. Ann Rheum Dis 2004;63:386-94

18. Rokita H, Szuba K. Regulation of acute phase reaction by transforming growth factor beta in cultured murine hepatocytes. Acta Biochim Pol 1991;38:241-9.

19. Mackiewicz A, Ganapathi MK, Schultz D, Brabenec A, Weinstein J, Kelley MF, et al. Transforming growth factor beta 1 regulates production of acute-phase proteins. Proc Natl Acad Sci U S A 1990;87:1491-5.

20. Valentijn RM, van Overhagen $H$, Hazevoet $H M$, Hermans J, Cats A, Daha MR, et al. The value of complement and immune complex determinations in monitoring disease activity in patients with systemic lupus erythematosus. Arthritis Rheum 1985;28:904-13.

21. Oku K, Atsumi T, Bohgaki M, Amengual O, Kataoka $\mathrm{H}$, Horita $\mathrm{T}$, et al. Complement activation in patients 
with primary antiphospholipid syndrome. Ann Rheum Dis 2009;68:1030-5.

22. Budman DR, Steinberg AD. Hematologic aspects of systemic lupus erythematosus. Current concepts. Ann Intern Med 1977;86:220-9.

23. De Bosscher K, Vanden Berghe W, Haegeman G. The interplay between the glucocorticoid receptor and nuclear factor-kappaB or activator protein-1: molecular mechanisms for gene repression. Endocr Rev 2003;24:488-522.

24. Kuznik A, Bencina M, Svajger U, Jeras M, Rozman B, Jerala R. Mechanism of endosomal TLR inhibition by antimalarial drugs and imidazoquinolines. J Immunol 2011;186:4794-804.

25. Lamphier M, Zheng W, Latz E, Spyvee M, Hansen H, Rose J, et al. Novel small molecule inhibitors of TLR7 and TLR9: mechanism of action and efficacy in vivo. Mol Pharmacol 2014;85:429-40.

26. Guiducci C, Gong M, Xu Z, Gill M, Chaussabel D, Meeker $T$, et al. TLR recognition of self nucleic acids hampers glucocorticoid activity in lupus. Nature 2010;465:937-41.

27. Sacks SH, Zhou W, Pani A, Campbell RD, Martin
J. Complement C3 gene expression and regulation in human glomerular epithelial cells. Immunology 1993;79:348-54.

28. Hamad OA, Nilsson PH, Wouters D, Lambris JD, Ekdahl KN, Nilsson B. Complement component C3 binds to activated normal platelets without preceding proteolytic activation and promotes binding to complement receptor 1 . J Immunol. 2010;184:2686-92.

29. Kayser W, Mueller-Eckhardt C, Bhakdi S, Ebert K. Platelet-associated complement C3 in thrombocytopenic states. $\mathrm{Br} \mathrm{J}$ Haematol 1983;54:353-63.

30. Polley MJ, Nachman R. The human complement system in thrombin-mediated platelet function. J Exp Med 1978;147:1713-26.

31. Tsubakio T, Tani P, Curd JG, McMillan R. Complement activation in vitro by antiplatelet antibodies in chronic immune thrombocytopenic purpura. $\mathrm{Br} \mathrm{J}$ Haematol 1986;63:293-300.

32. Thurm CW, Halsey JF. Measurement of cytokine production using whole blood. Curr Protoc Immunol. 2005 May;Chapter 7:Unit 7.18B. 